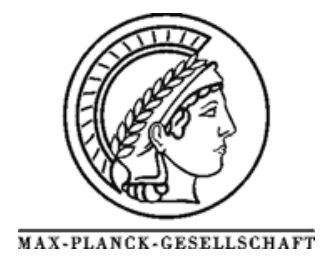

\title{
Solvent dependent shape and magnetic properties of doped ZnO Nanostructures
}

\author{
G. Clavel ${ }^{1,3}$, M.-G. Willinger ${ }^{1,4}$, D. Zitoun ${ }^{2, *}$, N. Pinna ${ }^{1,3, *}$ \\ ${ }^{1}$ Departament of Chemistry, CICECO, University of Aveiro, 3810-193 Aveiro, Portugal \\ ${ }^{2}$ AIME, Institut Charles Gerhardt, Université Montpellier II, Place Eugène Bataillon, 34095 Montpellier, France \\ ${ }^{3}$ Martin-Luther-Universität Halle-Wittenberg, Institut für Anorganische Chemie, Kurt-Mothes Str. 2, 06120 Halle \\ (Saale), Germany \\ ${ }^{4}$ Department of Inorganic Chemistry, Fritz-Haber-Institute of the MPG, Faradayweg 4-6, 14195 Berlin, Germany \\ "Corresponding author: zitoun@univ-montp2.fr, pinna@ciceco.ua.pt
}

\begin{abstract}
This study reports on a new solution phase synthesis leading to cobalt and manganese doped $\mathrm{ZnO}$ which have been theoretically predicted ferromagnetic at room temperature. The solvothermal synthesis involving the reaction of zinc and cobalt acetate or manganese oleate with benzyl alcohol leads to pure inorganic nanoparticles that are diluted magnetic semiconductors. The addition of an inert solvent, that is used in order to control the amount of benzyl alcohol, drastically influences the particles morphology and strongly affects the magnetic behaviors. Cobalt doped particles are paramagnetic or ferromagnetic depending on the synthesis conditions. In order to exclude the formation of secondary phases and/or metal clusters and to understand the role of the solvent on the magnetic properties, the local structure of $\mathrm{Co}^{2+}$ and $\mathrm{Mn}^{2+}$ in the wurtzite $\mathrm{ZnO}$ matrix were characterized by XRD, UV-Visible diffuse reflectance and electron paramagnetic resonance.
\end{abstract}

Keywords: Magnetic materials, Nanoparticles, Semiconductors, Zinc oxide

\section{Introduction}

Zinc oxide $(\mathrm{ZnO})$ has been the subject of numerous studies in the past ten years for its optical properties. The material is already used for the fabrication of highly efficient blue LEDs.[1] Doping has also been performed on $\mathrm{ZnO}$ in order to tune the emission from the bandgap and from the defects. These studies have certainly found some echo in another scientific area, namely the study of diluted magnetic semiconductors (DMS). Obviously, the use of carrier spin, in addition to the charge, appears very promising for the emergence of polarized emitters.[2, 3] A key requirement for the use of spin based electronic devices (spintronic) is the persistence of ferromagnetism above room temperature. Early studies on manganese doped $\mathrm{ZnO}$ have shown room temperature ferromagnetism, and $\mathrm{ZnO}$ has become one of the few oxides scheduled to be used in polarized emitters.

The fundamental origin of the observed magnetic behavior has attracted much attention since 2000. In an ex- tremely quoted paper, T. Dietl et al. reported a theoretical study on the Curie temperature of ferromagnetic DMS.[2] Interestingly, the experimental study of manganese doped zinc telluride supported the calculations and room temperature ferromagnetism was predicted for p-type manganese doped $\mathrm{ZnO}$ (and n-type cobalt doped $\mathrm{ZnO}$ ).

The revival of this already old field mainly occurs due to the assumption that room temperature ferromagnetism is indeed promoted by the semiconductor charge carriers, based on the so-called Zener model adapted to DMS. However, many of the claims of high-temperature ferromagnetism in DMS systems are controversial[4]. The high temperature synthesis process may explain the tendency of these materials to phase-separate into a $\mathrm{ZnO}$ matrix with transition metal inclusions.[2] The semiconducting properties would then originate from the matrix and the magnetic properties from the clusters. In addition, the exact origin of the observed magnetic behavior in these systems depends on the dopant/matrix system and the carrier concentration and thus on synthetic conditions. For example, it was 
shown that a secondary phase was the origin of the magnetic behavior in the case of a $\mathrm{ZnO} / \mathrm{MnO}_{2}$ system grown by high temperature solid state reaction.[5] Consequently, the main point of any new study relies on the exclusion of any secondary phase as origin for ferromagnetism.

$\mathrm{Mn}$ doped $\mathrm{ZnO}$ nanostructures from physical routes have been widely studied as thin films, [6-8] nanorods, [9] or nanowires.[10-13] Similar studies have been carried out on Co doped $\mathrm{ZnO}$ with thin films,[14-16] nanorods,[17, 18] and nanowires.[10, 19, 20] One-dimensional systems are particularly interesting for the study of DMS. The morphology offers a wide range of characterizations combined with a high potential for technological applications, as was shown for room temperature ultra-violet lasing.[1]

In two previous papers we reported on the synthesis and characterization of $\mathrm{Mn}$ and $\mathrm{Co}$ doped $\mathrm{ZnO}$ nanowires synthesized by a surfactant assisted route.[21, 22] The metal organic precursors were reacted in trioctylamine between $280-310{ }^{\circ} \mathrm{C}$. However, the amine is able to reduce metals at high temperature. Thus, the use of another solvent was needed in order to avoid any possible reduction of the magnetic dopants.

Moreover, solvent assisted synthesis and especially the "benzyl alcohol route" has several advantages over surfactant based routes.[23-25] It allows a good control of the crystal growth without the use of any additional ligands or templates. The final product is then exclusively inorganic and has a clean surface. In fact, its surface can be easily accessed in order to perform reactions (e.g. catalysis or gas sensing) [26, 27] and it can be functionalized in order to redisperse the particles in different kinds of solvents.[28, 29]

Few reports exist on the synthesis of zinc oxide in alcoholic media and in the majority of these cases, either surfactants are used to control the morphology [30, 31] or basic condition are needed to accomplish hydrolysis of the zinc precursor.[32-36] To the authors best knowledge, only two different studies involve the syntheses in pure alcohol [37, 38] and the possibility of doping zinc oxide by this approach has not been explored so far.

Here, we report on the synthesis and magnetic characterization of cobalt and manganese doped zinc oxide nanoparticles with different morphology grown by solvent assisted synthesis. The solution route allows the synthesis of gram-scale quantities of homogeneous nanostructures. This is an important prerequisite for a in depth analysis and macroscopic characterization of the obtained material. This synthetic method also enables the incorporation of several transition metal dopants into the $\mathrm{ZnO}$ nanowires, such as $\mathrm{Mn}, \mathrm{Fe}$ and Co. However, we limit this report to the manganese and cobalt-doped systems. We shall show that the doped samples present homogeneous doping precluding clustering and transition metal reduction. Furthermore, the observed magnetic behavior is strongly dependent on the solvents used for synthesis.

\section{Results and Discussion}

\section{Structural and morphological characterization}

This study focuses on the role of solvent on the morphology and magnetic properties of the obtained nanostructures. The nanoparticles were synthesized by reacting zinc acetate and a dopant precursor (cobalt acetate or manganese oleate) with different anisole/benzyl alcohol proportions at moderate temperature (table 1). Depending on the nature of dopant precursor used, the resulting nanoparticles are a green (cobalt) or yellow (manganese) powders.

Figure 1 shows the XRD patterns of the $\mathrm{ZnO}$ nanoparticles doped with cobalt (A) and manganese (B). They are plotted in logarithmic scale in order to enhance the presence of any impurity. The obtained XRD pattern is in agreement with the zincite structure. No additional reflections are observed even for the particles including the largest amount of dopant indicating that there are no additional crystalline structures present in the samples. In all cases, wurtzite is the only crystalline phase. The lattice
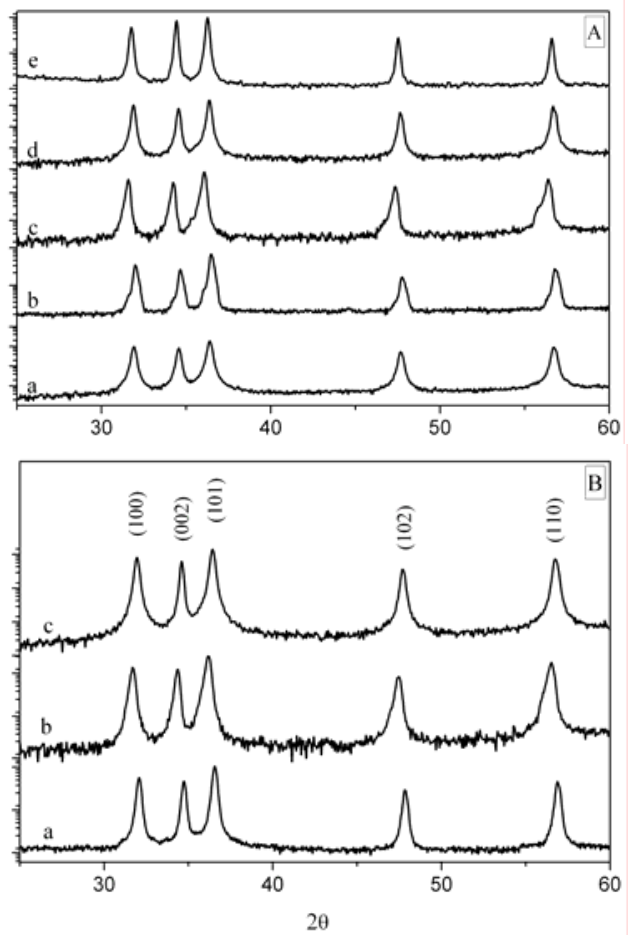

Figure 1: Log scale XRD patterns of Co (A) and Mn (B) doped nanoparticles synthesized with different amount of benzyl alcohol/anisole, the indexation of wurtzite structure (JCPDS Card No 36,1451 ) is given in (B). (A) a) Co $0.77 \%$ in benzyl alcohol, b) Co $3.88 \%$ in benzyl alcohol, c) Co $0.81 \%$ in benzyl alcohol/anisole $(5 / 95)$, d) Co $4.09 \%$ in benzyl alcohol/anisole $(5 / 95)$, e) Co $0.65 \%$ in anisole with traces of benzyl alcohol. (B) a) Mn $0.56 \%$ benzyl alcohol, b) Mn $0.66 \%$ in benzyl alcohol/anisole $(5 / 95)$, c) $\mathrm{Mn}$ $0.86 \%$ in benzyl alcohol/anisole (5/95). 
Table 1: Experimental conditions, doping efficiency, morphological results and magnetic state $\left(\mathrm{A}=\right.$ Anisole, $\mathrm{BA}=$ benzyl alcohol). ${ }^{*}$ For each doped sample a paramagnetic component is always present.

\begin{tabular}{|c|c|c|c|c|c|}
\hline Solvents & Dopants & $\begin{array}{c}\text { Nominal } \\
\text { doping }(\%)\end{array}$ & $\begin{array}{l}\text { Effective doping } \\
(\%)\end{array}$ & Morphology & Magnetic coupling* \\
\hline $\mathrm{BA}$ & $\mathrm{Co}$ & 1.06 & 0.77 & Nanoparticles and nanorods & Ferromagnetic \\
\hline BA & Co & 4.90 & 3.88 & $\begin{array}{l}\text { Rodlike morphology, inhomogeneous } \\
\text { size }\end{array}$ & Ferromagnetic \\
\hline $\mathrm{BA}$ & $\mathrm{Mn}$ & 1.04 & 0.56 & $\begin{array}{c}\text { Elongated, triangles and hexagonal } \\
\text { nanoparticles }\end{array}$ & Antiferromagnetic \\
\hline A/BA $(95 / 5 \%)$ & none & 0.00 & 0.00 & Small rods & \\
\hline A/BA $(95 / 5 \%)$ & Co & 1.22 & 0.81 & Small rods & Antiferromagnetic \\
\hline A/BA $(95 / 5 \%)$ & Co & 1.99 & 1.16 & $\begin{array}{l}\text { Rodlike morphology, inhomogeneous } \\
\text { size }\end{array}$ & Antiferromagnetic \\
\hline A/BA $(95 / 5 \%)$ & Co & 5.40 & 4.09 & $\begin{array}{l}\text { Rodlike morphology, inhomogeneous } \\
\text { size }\end{array}$ & Antiferromagnetic \\
\hline A/BA $(95 / 5 \%)$ & $\mathrm{Mn}$ & 1.16 & 0.66 & Rods & Antiferromagnetic \\
\hline A/BA $(95 / 5 \%)$ & $\mathrm{Mn}$ & 2.07 & 0.86 & Rods with inhomogeneous size & Antiferromagnetic \\
\hline $\mathrm{A}+\operatorname{traces} \mathrm{BA}$ & Co & 0.99 & 0.65 & Nanowires & Antiferromagnetic \\
\hline
\end{tabular}

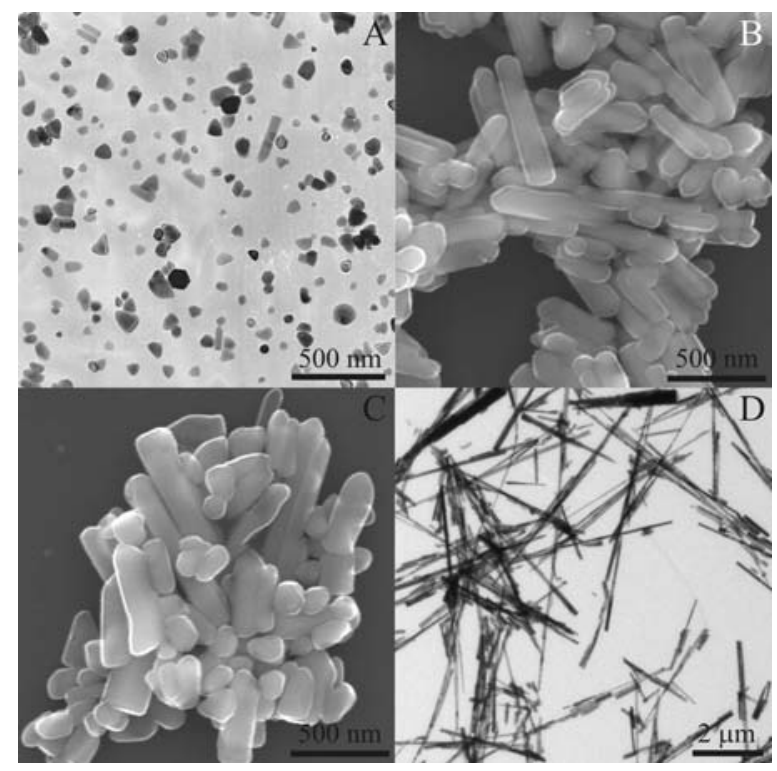

Figure 2: (A) TEM image of $0.56 \% \mathrm{Mn}$ doped $\mathrm{ZnO}$ in pure benzyl alcohol, (B) SEM image of pure $\mathrm{ZnO}$ synthesized in benzyl alcohol/anisole (5/95), (C) SEM image of $0.81 \%$ Co doped $\mathrm{ZnO}$ synthesized in benzyl alcohol/anisole (5/95), (D) TEM image of $0.65 \%$ Co doped $\mathrm{ZnO}$ in anisole with traces of benzyl alcohol.

constant does not show any significant shift, certainly resulting from the close values of ionic radii in the case of zinc and cobalt $\left(\mathrm{Zn}^{2+} \sim 0.60 \AA, \mathrm{Co}^{2+} \sim 0.58 \AA\right)$. A shift is supposed to occur only for manganese doping $\left(\mathrm{Mn}^{2+} \sim 0.66\right.$ $\AA)$. Nevertheless, in this report manganese sample are only slightly doped (less than $1 \%$ ) and probably not induce a detectable shift.

The morphology of the products was examined with scanning electron microscopy (SEM), transmission electron microscopy (TEM) and infrared (IR) spectroscopy. Figure 2 shows electron microscopy images demonstrating the morphological control of doped and undoped $\mathrm{ZnO}$ nanopar- ticles. The growth of zinc oxide exclusively in benzyl alcohol results in a heterogeneous sample where nanoparticles coexist with small rods (not shown). Cobalt doping in pure benzyl alcohol leads to rods of inhomogeneous diameter and aspect ratio (not shown), while manganese doping leads to triangular or hexagonal particles in coexistence with small rods (Figure 2A). The use of an inert solvent (anisole) allows to control the amount of benzyl alcohol and influences the growth and hence, the morphology of the obtained zinc oxide. Figure $2 \mathrm{~B}$ shows rods of approximately $400 \times 100 \mathrm{~nm}$ obtained with $5 \%$ benzyl alcohol in anisole. In the case of Co-doped samples, SEM observations (Figure 2C) demonstrate that very short rods are formed. Manganese doping leads to the formation of rods with higher average length (not shown) in the case of the synthesis with $5 \%$ benzyl alcohol in anisole. Further decrease of the benzyl alcohol content improves the aspect ratio; however, a drastic decrease of the synthesis yield is observed. Thus, in the manuscript we focused on samples synthesized with at least $5 \%$ of benzyl alcohol in anisole. Nevertheless, in order to further increase the aspect ratio, the synthesis of Co-doped $\mathrm{ZnO}$ was performed in pure anisole using a Teflon cup which was previously used for a synthesis of $\mathrm{ZnO}$ in pure benzyl alcohol (cf. also experimental section). In this case, traces of benzyl alcohol (< $200 \mu 1$ as detected by GC-MS), which were absorbed by the Teflon at high temperature, were slowly released allowing a fine control of the reaction kinetics (Figure 2D).

Select area electron diffraction (SAED) and high resolution microcopy (HRTEM) were used to investigate the growth orientation of $\mathrm{ZnO}$. Figure $3 \mathrm{~A}$ shows a TEM image of one rod of a cobalt doped sample. The corresponding diffraction pattern can be indexed to the hexagonal wurtzite phase of zinc oxide in agreement with XRD spectra. Furthermore, the rods are single-crystalline and elongated in the [0001] direction, i.e. along the $\mathrm{c}$ axis. This is in agreement with the reported preferential orientation 


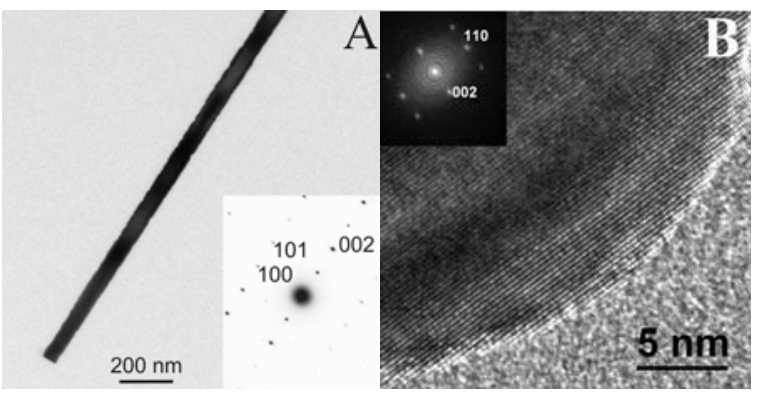

Figure 3: (A) TEM picture of single rod with in inset the corresponding SAED pattern $(0.65 \%$ Co). (B) HRTEM image of the tip region of a single particle. Separations between the lattice fringes were abstracted from the power spectrum (inset) and are in agreement with the $0002(2.60 \AA)$ and $11-10(1.38 \AA)$ directions, respectively $(3.88 \% \mathrm{Co})$.

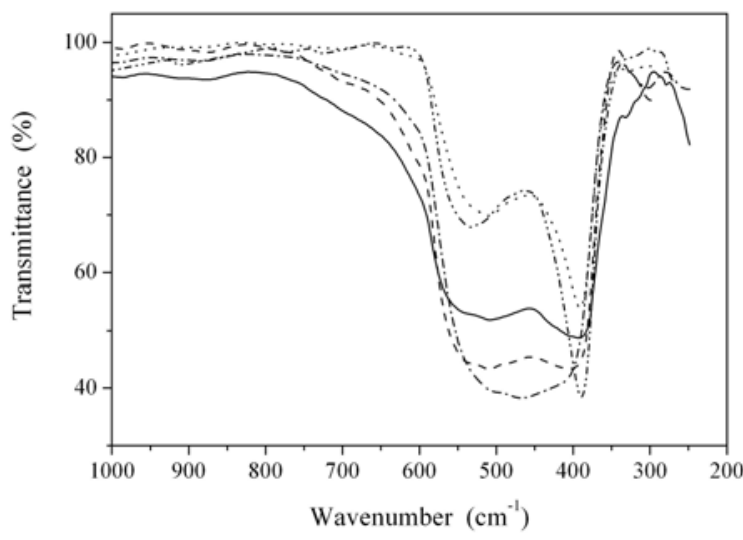

Figure 4: FT-IR spectra of pure $\mathrm{ZnO}$ in benzyl alcohol/anisole (5/95) (full line), $0.81 \%$ Co doped $\mathrm{ZnO}$ synthesized in benzyl alcohol/anisole (5/95) (dashed line), 4.09\% Co doped $\mathrm{ZnO}$ synthesized in benzyl alcohol/anisole (5/95) (dot-dashed line), $0.66 \% \mathrm{Mn}$ doped $\mathrm{ZnO}$ synthesized in benzyl alcohol/anisole (5/95) (dotted line), $0.65 \%$ Co doped $\mathrm{ZnO}$ synthesized in anisole with traces of benzyl alcohol (dot-dot-dashed line).

growth in solution based on the different polarity of the crystal planes. [39, 40] A high resolution TEM image recorded from the tip region of a particle and the corresponding power spectrum is shown in figure $3 \mathrm{~B}$. The tip shows a nice crystallinity and clear lattice fringes can be observed. Changes in the contrast are due to the increasing thickness from the front most tip towards the inner part. The separation between the lattice fringes along the tube axis is in agreement with the 0002 plane spacing $(2.60 \AA)$. In the direction perpendicular to the tube axis, the 11-10 planes with a spacing of $1.38 \AA$ are observed. In contrast to the SAED, the power spectrum of the tip only shows the allowed 0002 spots.

IR spectroscopy was performed to confirm the evolution of the morphology on the macroscopic scale. Zinc oxide presents a wurtzite structure with two transverse optical modes at $\omega_{\mathrm{T}}=377 \mathrm{~cm}^{-1}$ and $\omega_{\mathrm{T} \perp}=406 \mathrm{~cm}^{-1}$ for bulk crystals. [41] The bands are displaced according to the shape factor g.[41] For spherical $\mathrm{ZnO}$ nanocrystals ( $\mathrm{g}=$ 0.33 ), the movement of the bands is such that they overlap to give rise to a simple band at $460 \mathrm{~cm}^{-1}$. [41] An increase in the splitting of the absorption bands takes place in going from the sphere to the cylinder. Therefore, this feature can be used to define an average fibrous grade of the $\mathrm{ZnO}$ particles.

Pure $\mathrm{ZnO}$ and $\mathrm{Co}$ doped $\mathrm{ZnO}$ made in a mixture of benzyl alcohol/anisole 5/95\% show only a broad band centered at $460 \mathrm{~cm}^{-1}$ with and without a small splitting, respectively (Figure 4). This is in good agreement with the TEM/SEM findings showing short rods. For the Mn doped $\mathrm{ZnO}$ synthesized with the same benzyl alcohol/anisole ratio the particles present a higher aspect ratio, thus the splitting is better visible and the width of the IR absorption are much sharper. The same trend is observed in the case of Co doped sample synthesized in anisole in the presence of traces of benzyl alcohol. The shape factor could be determined for the two latter samples, the splitting value $\Delta v=$ 120 and $147 \mathrm{~cm}^{-1}$, respectively correspond to $\mathrm{g} \leq 0.02$ in good agreement with electron microscopy data.
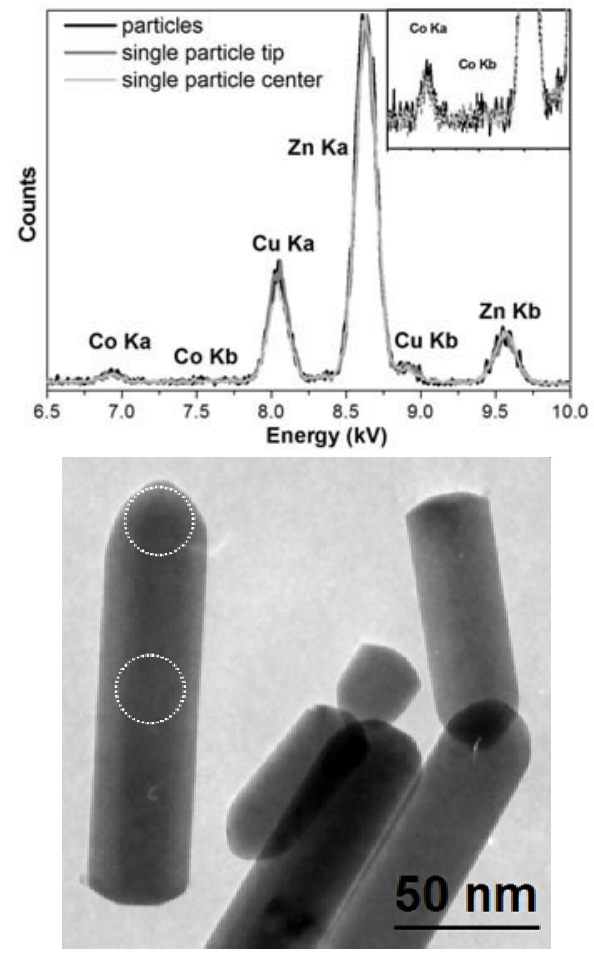

Figure 5: Left: EDX spectra recorded from regions containing a number of particles and spectra recorded along single particles reveal a homogeneous distribution of Co. Right side: region from which the EDX spectra shown here were recorded. Circles indicate regions where the spot was focused for the detection of eventual variations in the Co concentration along a single particle $(3.88 \%$ Co).

After the morphologic characterization the concentration and homogeneity of the dopant was investigated. The doping concentration measured by ICP-AES comes out to be slightly lower than the quantity of precursors introduced (about 30\%). The cobalt concentration varies from less than $0.5 \%$ to (larger than) $4 \%$ depending on the amount of cobalt precursor introduced, the manganese one 
Scheme 1: Reaction of benzyl alcohol and zinc acetate. (A) hydroxylation of zinc acetate, (B) condensation pathways and (B 2b) esterification of benzyl alcohol by acetic acid. $\mathrm{L}$ represent any kind of ligand coordinated to a $\mathrm{Zn}$ atom $(\mathrm{L}=\mathrm{OH}$, acetate, $\mathrm{O}-\mathrm{Zn})$.

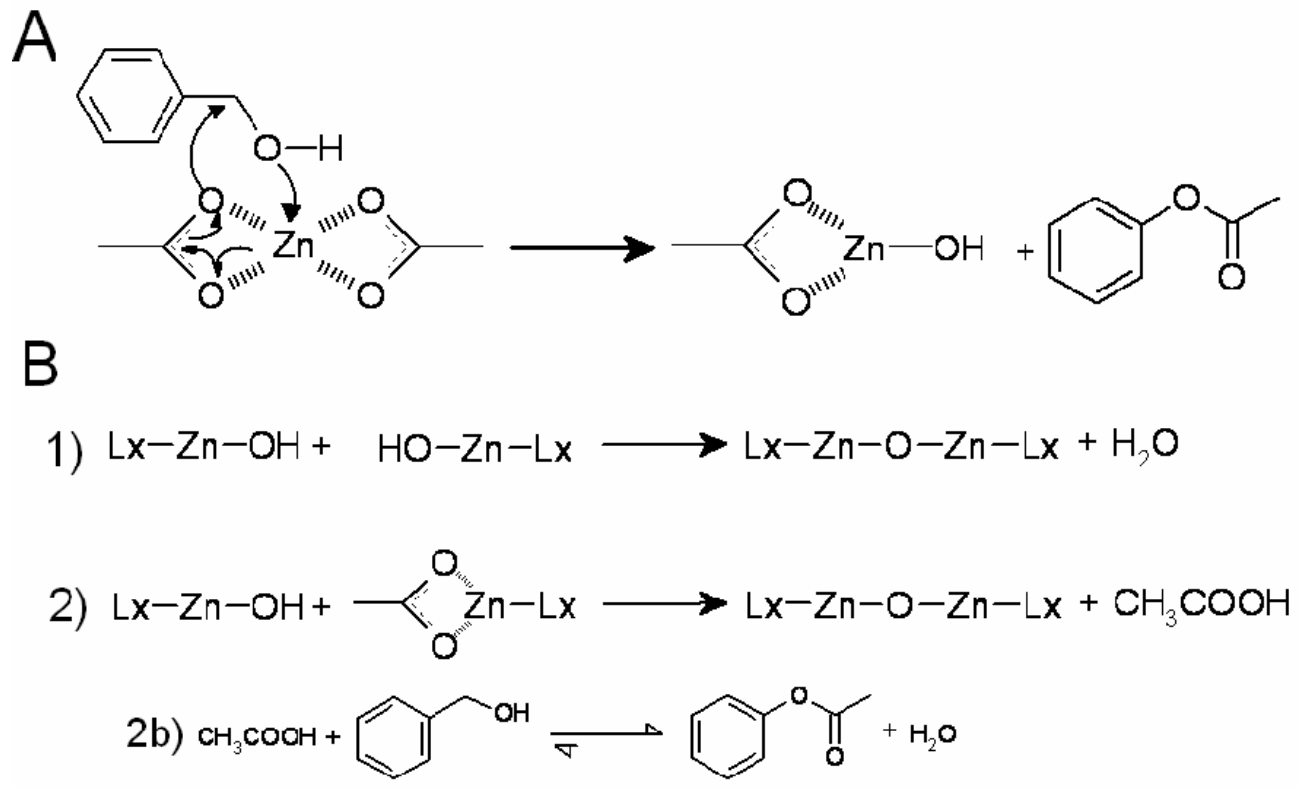

from 0.5 to $1 \%$ (table 1 ). In order to check the homogeneity of the cobalt distribution within the $\mathrm{ZnO}$ matrix, EDX spectra were recorded in the TEM (see figure 5). The spectra reveal that the Co concentration is homogeneous. At least, the variation of the Co concentration for different particles as well as the variations observed when measuring at different points along single particles lies below the detection limit. In addition to EDX, also EELS spectra were recorded. Due to the relatively large thickness of the particles, the Co white lines peaked only slightly above the huge background caused by the inelastic scattering processes. Again, the expected variations were below the detection limit. Therefore it can be concluded that the Co is indeed homogeneously distributed in the synthesized particles. This in also agreement with the HRTEM investigations reported above, where no inclusions of a second phase have been observed.

In order to understand the crystal growth and the kinetic formation of $\mathrm{ZnO}$, the mechanism of the reaction was studied. Nuclear magnetic resonance (NMR) was used to analyze the composition of the solvent mixture after reaction. It contains benzyl acetate as main by-product (cf. experimental section). Formation of an ester was already observed by $\mathrm{Du}$ et al. during the reaction of zinc acetate and ethanol[37] and in more complex media, between zinc acetate and 1,12-dodecanediol by Joo et al.[30] Such a synthetic approach is well established in field of nonaqueous sol-gel processes and called ester elimination.[25] The formation of zinc oxide following this route engages hydroxylation and condensation reactions (Scheme 1). During hydroxylation (Scheme 1A) the acetate functions are replaced by hydroxide groups leading to zinc hydroxide derivative and benzyl acetate. Two competitive condensation reactions can then take place: i) between two freshly formed hydroxide groups (Scheme 1B1) with the formation of water, or ii) between a hydroxide and an acetate function with release of acetic acid (Scheme 1B2). Acetic acid was not detected in final mixture probably because of its immediate reaction with benzyl alcohol producing benzyl acetate as illustrated in scheme 1B2b. Esterification is an equilibrated reaction. However, as it took place in a large excess of alcohol the equilibrium is strongly shifted to the ester formation, thus explaining the absence of acid.

NMR quantification points to the complete reaction of acetate species with benzyl alcohol producing two benzyl acetate molecules per $\mathrm{Zn}$ atom. It is know that carboxylates act as surfactant in controlling the growth of nanoparticles because they bind to oxide surfaces. In a previous benzyl alcohol route it was even found that carboxylate species bind so strongly to sub-nanometer thick rare-earth oxide platelets, than they block any further growth.[42] In the present case acetates cannot act as surfactants because they are totally consumed during the esterification reaction. Furthermore, water produced during the reaction could hydrolyze zinc precursors increasing overall reaction kinetics. These effects migth explain the poor control over the crystal growth compared to other reactions involving benzyl alcohol.[23,24].

As opposed to what was pointed out in other studies [33, 41, 43], the size and shape controls are not affected by the concentration of zinc precursor. Instead, the concentration of benzyl alcohol seems to play a role. This is obviously related to the fact that the concentration of zinc precursor is much smaller compared to the one of benzyl alcohol. Hence, the variation of zinc concentration does not change the kinetics of the reaction. On the other hand, reduction of the quantity of alcohol by using an inert cosolvent affects the kinetic (and probably the hydroxylation rate) as the observed aspect ratio increase substantially. Additionally, the nature and the concentration of dopants 


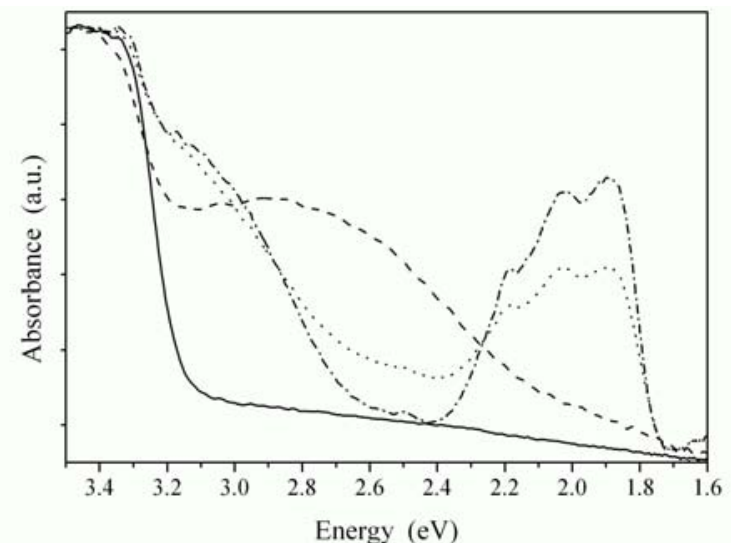

Figure 6: Diffuse reflectance UV-Visible of pure $\mathrm{ZnO}$ in benzyl alcohol/anisole (5/95) (full line), $0.81 \%$ Co doped $\mathrm{ZnO}$ synthesized in benzyl alcohol/anisole (5/95) (dotted line), $0.77 \%$ Co doped $\mathrm{ZnO}$ synthesized in pure benzyl alcohol (dot-dashed line), $0.66 \%$ $\mathrm{Mn}$ doped $\mathrm{ZnO}$ synthesized in benzyl alcohol/anisole (5/95) (dashed line).

influence slightly the morphology. In the case of manganese doped particles a better morphological control can be explained by the presence of oleate molecules which behave as a surfactant.

After determining the morphology, purity, and dopant concentration, we ascertained the local environment of the cobalt using electronic spectroscopy. Diffuse reflectance UV-Visible measurements of pure $\mathrm{ZnO}$ and $\mathrm{ZnO}$ doped with $\mathrm{Co}$ and $\mathrm{Mn}$ are shown in figure 6. The spectrum of pure $\mathrm{ZnO}$ exhibits typical exciton band gap absorption around $3.3 \mathrm{eV}$. Co-doped $\mathrm{ZnO}$ spectra show additional optical absorptions at 2.18, 2.03 and $1.9 \mathrm{eV}$ due to the ${ }^{4} \mathrm{~A}_{2}(\mathrm{~F}) \rightarrow{ }^{2} \mathrm{~A}_{1}(\mathrm{G}),{ }^{4} \mathrm{~A}_{2}(\mathrm{~F}) \rightarrow{ }^{4} \mathrm{~T}_{1}(\mathrm{P}),{ }^{4} \mathrm{~A}_{2}(\mathrm{~F}) \rightarrow{ }^{2} \mathrm{E}(\mathrm{G})$ transitions which are characteristic of $\mathrm{Co}^{2+}$ in a tetrahedral crystal field.[44, 45] A modification of the excitonic peak emerges after doping, which is usually attributed as a red shift of the band gap due to sp-d exchange interactions [46-48]. However, we assume that this modification is probably caused by a charge transfer as explained by Gamelin et al. in Table 1 of ref. [15]. Indeed, the band gap edge of $\mathrm{ZnO}$ is still present at $3.3 \mathrm{eV}$ and is only partially overlapping with this new band at around $3 \mathrm{eV}$. The spectrum of the Mn-doped sample depicts a broad absorption peak centered at $2.7 \mathrm{eV}$. Such a band is often attributed to the $\mathrm{Mn}^{2+}$ transition ${ }^{6} \mathrm{~A}_{1} \rightarrow{ }^{4} \mathrm{~T}_{1}(\mathrm{G})$.[49, 50] However, the exact origin of this band is not unequivocally assigned; by considering the width of this absorption it is justifiable to attribute it to a charge-transfer.[6, 51] Finally, electron spectroscopy is in agreement with $\mathrm{Co}$ and $\mathrm{Mn}$ doped $\mathrm{ZnO}$ presenting a homogeneous distribution of the dopants in a tetrahedral environment.

\section{Magnetic properties}

We complemented the study of the dopant distribution and environment with electron paramagnetic resonance spectroscopy (EPR). This technique is a very efficient tool to determine the environment of paramagnetic species in a host lattice, such as Mn in several II-VI semiconductors, [52-54] or $\mathrm{Co}$ in $\mathrm{SnO}_{2}$. [55] EPR is a powerful tool for the investigation of the local structure and the distribution of the $\mathrm{Mn}^{2+}$ and $\mathrm{Co}^{2+}$ in host lattices.

EPR measurements were performed on powders. Below $1.0 \% \mathrm{Mn}$ doping, the spectrum shows two contributions (Figure 7): (i) A broad resonance resulting from antiferromagnetic interactions of $\mathrm{Mn}^{2+}$ ions and (ii) a sextuplet from isolated spins (Figure 7A). Above this Mn concentration, only a broad signal was measured at temperatures between $100 \mathrm{~K}$ and $300 \mathrm{~K}$. The observed hyperfine splitting $\left(\Delta \mathrm{H}_{\mathrm{pp}}=76\right.$ Gauss, $\left.\Delta \mathrm{H}_{\mathrm{pp}}=73 \mathrm{~cm}^{-1}\right)$ (Figure 7B) is in close agreement with the bulk value for dilute $\mathrm{Mn}$ in $\mathrm{ZnO}$ matrix $\left(\Delta \mathrm{H}_{\mathrm{pp}}=76\right.$ Gauss) and precludes the occurrence of surface state $\mathrm{Mn}^{2+}$ atoms $\left(\Delta \mathrm{H}_{\mathrm{pp}} \sim 90\right.$ Gauss). Contrary to a previous study on $\mathrm{Mn}$ doped $\mathrm{ZnO}$ clusters, the EPR data therefore gives no evidence for the presence of isolated surface state $\mathrm{Mn}^{2+}$ atoms coexisting with core $\mathrm{Mn}^{2+}$.[56] In the present case the manganese ions are distributed substitutionally in tetrahedral sites.

In the case of cobalt for particles synthesized in pure benzyl alcohol and in anisole with traces of benzyl alcohol a series of EPR spectra was recorded as a function of temperature (Figure 8). At room temperature, the samples do not display any resonance. At low temperature (below 100 $\mathrm{K})$, the spectra are dominated by an intense broad resonance $(\mathrm{H}=1500$ Gauss, $\mathrm{g}=4.43)$ and a weaker band $(\mathrm{H}=$ 3000 Gauss, $g=2.23$ ).
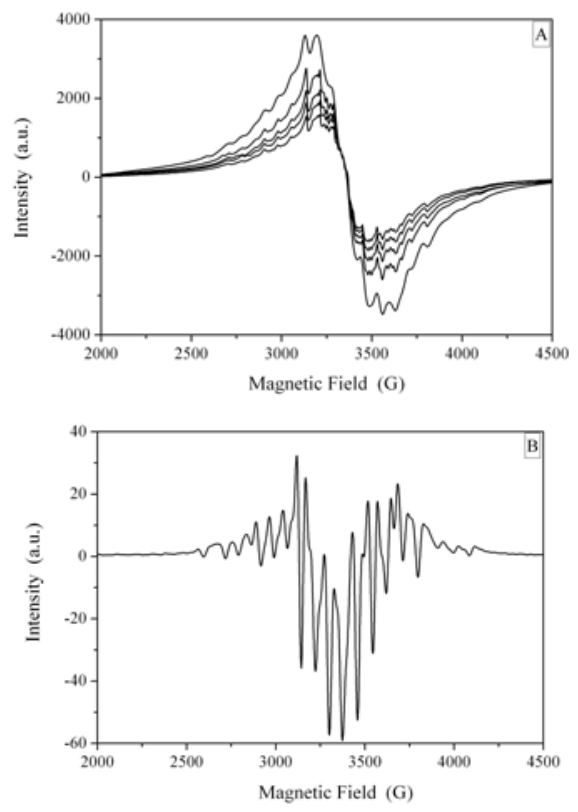

Figure 7: (A) Temperature-dependent EPR spectra (intensity decreases with increasing temperature, $\mathrm{T}=100,150,200,250$ and $300 \mathrm{~K}$ ) of $0.56 \% \mathrm{Mn}$ doped $\mathrm{ZnO}$ synthesized in benzyl alcohol. (B) First derivative of the spectrum (A) collected at $\mathrm{T}=100 \mathrm{~K}$. 
A deep analysis of the EPR data relies on the assignment of each resonance to the cobalt local environment. Even though the occurrence of isolated small clusters cannot grant for the observed ferromagnetic ordering at room temperature, the need to rule out cobalt clustering stands as the main focus of this study. In particular, the cobalt oxidation state needs to be enlightened by the study of Co (0) clusters to preclude any metal clustering in the $\mathrm{ZnO}$ matrix. There are few examples in the literature on the use of EPR to fully characterize cobalt based molecular clusters. The study of $\left.\left[\mathrm{Co}_{6}\left(\mu_{3}-\mathrm{S}\right)_{8}\left(\mathrm{PEt}_{3}\right)_{6}\right]\left(\mathrm{PF}_{6}\right)\right]$ by EPR spectroscopy reveals a fine resonance interpreted by a $\mathrm{g}$ tensor $\left[g_{x}=2.35, g_{y}=2.04, g_{z}=1.95\right]$.[57] Other studies on $\left[\mathrm{Co}_{5} \mathrm{MoN}(\mathrm{CO})_{14}\right]^{2-}$ and $\left[\mathrm{Co}_{5} \mathrm{MoN}(\mathrm{CO})_{14} \mathrm{AuPPh}_{3}\right]^{-}$show similar results.[58] Furthermore, the samples studied in the present work do not exhibit any resonance at room temperature (Figure 8B). Therefore, the EPR data rule out the presence of molecular or metal clusters.
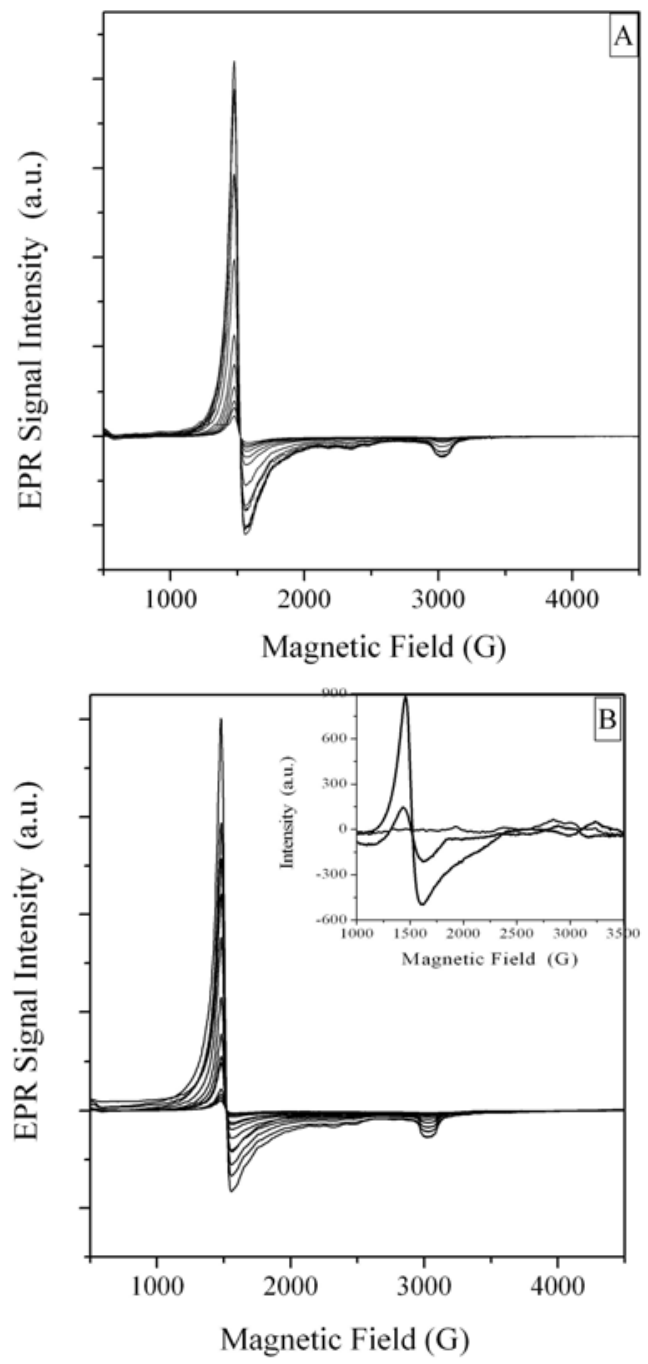

Figure 8: Temperature-dependent EPR spectra (intensity decreases with increasing temperature) of (A) $0.65 \%$ Co doped $\mathrm{ZnO}$ synthesized in anisole with traces of benzyl alcohol in the temperature range $2.8-70 \mathrm{~K}$, (B) $3.88 \% \mathrm{Co}$ doped $\mathrm{ZnO}$ in pure benzyl alcohol in the range of temperature 3.7-82.8 K. (inset) Spectra collected at $\mathrm{T}=100,150$ and $300 \mathrm{~K}$ (intensity decreases with increasing temperature).
In a previous study, cobalt nanoparticles have been elaborated using chemical routes. The material consisted in a dispersion of nanoparticles displaying a narrow size distribution in a polymer matrix. The low concentration of clusters prevented the presence of dipolar interactions between neighbouring particles, which made easy the interpretation of the magnetic measurements. The polymer matrix interacted poorly with the surface of the particles. As a consequence, the nanoparticles reproduced some of the unusual properties of gas phase clusters such as a high magnetic moment and high anisotropy constant.[59-62]

The high-frequency ferromagnetic resonance (HFFMR) spectra of two systems of Co nanoparticles with sizes of 1.5 and $1.9 \mathrm{~nm}$ (called Coll.1 and Coll.2, respectively in ref. [60]) have been measured in the superparamagnetic (SP) regime as a function of the temperature.[60] They reveal broad absorption spectra $(\Delta \mathrm{B}=1250$ Gauss at $\mathrm{T}=298 \mathrm{~K}$ for Coll.1). The uncorrected values of $\mathrm{g}_{\text {eff }}=2.38$ and 2.36 at room temperature (for Coll.1 and Coll.2 respectively) were well above the bulk values, 2.06 and 2.18 for fcc and hcp crystalline structures respectively. By taking into account the correction due to the strong damping parameter $\alpha,\left(g_{\text {eff }}=g \sqrt{1+\alpha^{2}}\right)$, the final $g$ values were found to be the same in the range of 2.21, just above the $g$ value of the hcp phase. The $g_{\text {eff }}$ and $\Delta \mathrm{B}$ increased as the inverse of temperature. At $100 \mathrm{~K}$, the cobalt nanoparticles Coll.1 displayed a resonance centered at $\mathrm{g}_{\text {eff }}=2.6$ with $\Delta \mathrm{B}$ $=1750$ Gauss. At $10 \mathrm{~K}$, according to the behavior observed between 100 and $298 \mathrm{~K}$, the cobalt clusters would display a resonance centered at $\mathrm{g}_{\mathrm{eff}}=5.5$ with $\Delta \mathrm{B}>2000$ Gauss.

The observed ferromagnetic resonance for the small cobalt clusters in a matrix is found to be drastically different from the observed one for cobalt doped $\mathrm{ZnO}$ nanoparticles. In the latter case, the $\mathrm{g}$ values do not vary with temperature and the linewidth is $\Delta \mathrm{B}=80$ Gauss for all samples, a very low value compared to Co clusters. Therefore, the EPR study would preclude the cobalt clustering in the oxide matrix or the occurrence of isolated cobalt nanoparticles.

The reciprocal EPR intensity vs. temperature is plotted in Figure 9. Curie's Law predicts that this would be a straight line for isolated, paramagnetic $\mathrm{Co}^{2+}$ ions; however, we observe a deviation from Curie behavior for samples synthesized in pure benzyl alcohol in the temperature range 35-40 K. On the contrary, samples synthesized in anisole with only traces of benzyl alcohol do not show any discrepancy from a Curie law for the same cobalt content.

With the environment of the metal dopant determined and preclusion of any clustering and/or dopant reduction, we next examined the magnetic properties with a SQUID magnetometer. In the case of manganese, for all concentrations and all synthesis conditions, the pristine samples never show any deviation from a paramagnetic behavior. The ZFC-FC measurements show no deviation from Curie law (not shown). The magnetic properties of cobalt doped samples were investigated as a function of $\mathrm{Co}$ concentration and synthesis solvent. Magnetization vs. 


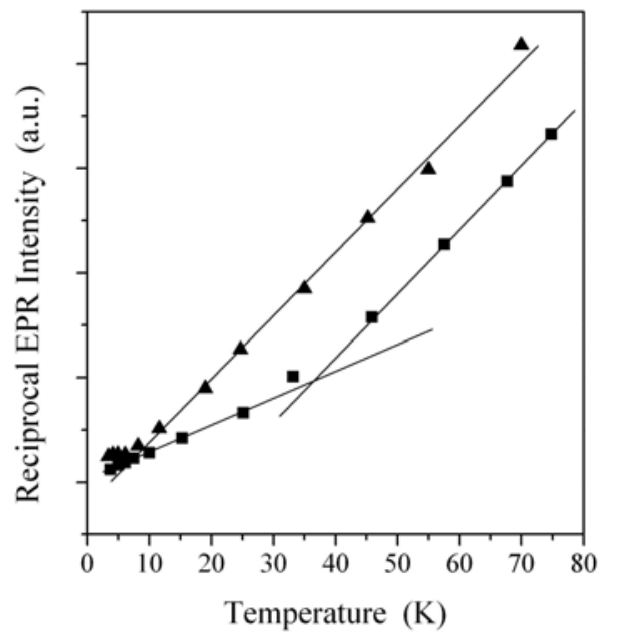

Figure 9: Reciprocal EPR intensity versus temperature of $0.65 \%$ Co doped $\mathrm{ZnO}$ synthesized in anisole with traces of benzyl alcohol (triangle), 3.88\% Co doped $\mathrm{ZnO}$ in pure benzyl alcohol (square).

Field (M-H) measurements at 2 and $300 \mathrm{~K}$ are depicted in figure 10 for synthesis in different solvent ratio. At low temperature, nanoparticles synthesized in benzyl alcohol/anisole (5/95) do not exhibit magnetic hysteresis for any concentration. At $\mu_{0} \mathrm{H}=5.0 \mathrm{~T}$, the magnetization does not saturate and reaches values from 2.1 to $3.6 \mu_{\mathrm{B}} / \mathrm{Co}$ atom depending on the cobalt concentration. The maximum is found for $1.16 \%$ doping (Figure 10A). The Langevin fit gives an estimated value of $\mathrm{M}_{\mathrm{S}}=3.6 \mu_{\mathrm{B}} / \mathrm{Co}$, close to the expected value for isolated $\mathrm{Co}^{2+}(3.5 \mu \mathrm{B} / \mathrm{Co})$. The lower magnetization observed in some samples is due to an antiferromagnetic coupling between a small fraction of $\mathrm{Co}^{2+}$ ions. At room temperature, all samples synthesized in anisole are paramagnetic (Figure 11B). However, the samples synthesized in pure benzyl alcohol exhibit a square loop with a coercive field of $17 \mathrm{mT}$ (Figure 10B and 11). At room temperature, the magnetic moment per cobalt atom is still reaching the value of $0.80 \mu_{\mathrm{B}}$ for an applied field of $\mu_{0} \mathrm{H}=1.0 \mathrm{~T}$ (Figure 11B). This unusual feature for a DMS makes the study of this material very exciting for application as a multifunctional (magnetic and optical) probe.

A controlled experiment on pure $\mathrm{ZnO}$ was performed to rule out any ferromagnetism originated from point defects (Figure 12A). The expected diamagnetism is compensated at low temperature by a paramagnetism that certainly results from paramagnetic species absorbed on surface or intrinsic defects.[63] However, the paramagnetism observed in this case is at least three orders of magnitude lower than in cobalt doped samples (see below).

We have also measured magnetization vs. temperature (M-T curves) (Figure 12B). The ZFC-FC measurements show no deviation from Curie law for nanoparticles synthesized in benzyl alcohol/anisole (5/95). However, in the case of the synthesis in pure benzyl alcohol, the ZFCFC deviate from a Curie law beyond $30 \mathrm{~K}$. Above this temperature the magnetic moment is stable at a non zero value.

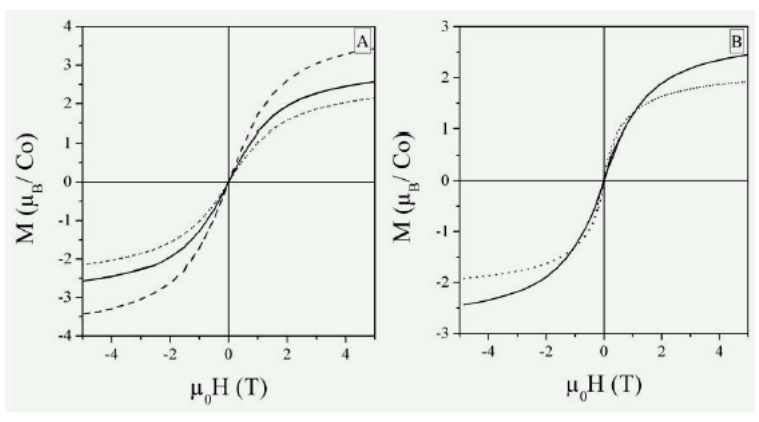

Figure 10: Magnetization versus field loops at $2 \mathrm{~K}$ of (A) $0.81 \%$ Co doped $\mathrm{ZnO}$ synthesized in benzyl alcohol/anisole (5/95) (full line), $1.16 \%$ Co doped $\mathrm{ZnO}$ synthesized in benzyl alcohol/anisole (5/95) (dashed line), 4.09\% Co doped ZnO synthesized in benzyl alcohol/anisole (5/95) (dotted line) and (B) $0.77 \%$ Co doped $\mathrm{ZnO}$ in pure benzyl alcohol (full line) $3.88 \% \mathrm{Co}$ doped $\mathrm{ZnO}$ in pure benzyl alcohol (dotted line).
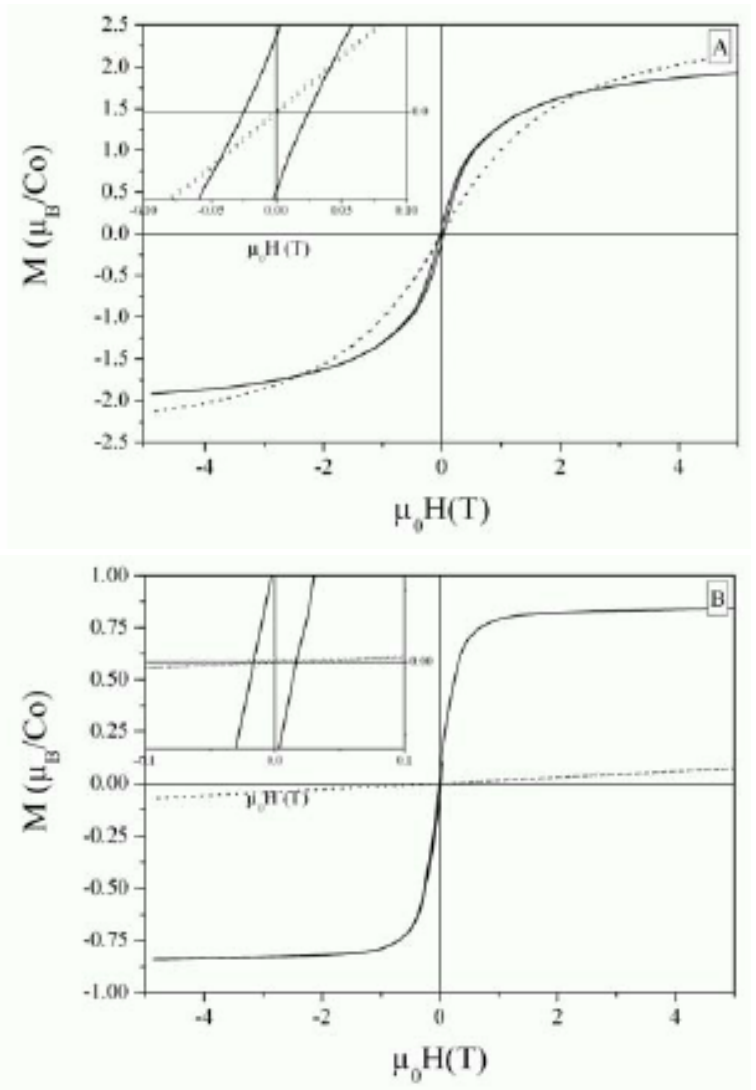

Figure 11: (A) Magnetization versus field at $2 \mathrm{~K}$ of $3.88 \% \mathrm{Co}$ doped $\mathrm{ZnO}$ in pure benzyl alcohol (full line), 4.09\% Co doped $\mathrm{ZnO}$ synthesized in benzyl alcohol/anisole (5/95) (dotted line).

(B) Magnetization versus Field at $300 \mathrm{~K}$ of $3.88 \%$ Co doped $\mathrm{ZnO}$ in pure benzyl alcohol (full line), 4.09\% Co doped $\mathrm{ZnO}$ synthesized in benzyl alcohol/anisole (5/95) (dotted line).

The temperature dependence displays a behavior typical of the coexistence of ferromagnetic and paramagnetic phases. For temperatures around $35-40 \mathrm{~K}$ the magnetization begins to deviate from paramagnetism, as determined from a plot of the inverse magnetic susceptibility versus temperature (not shown). Therefore, the observed ferromagnetism arises from the ferromagnetically coupled $\mathrm{Co}^{2+}$. The magnetic behavior of these nanoparticles can thus be most reasonably 

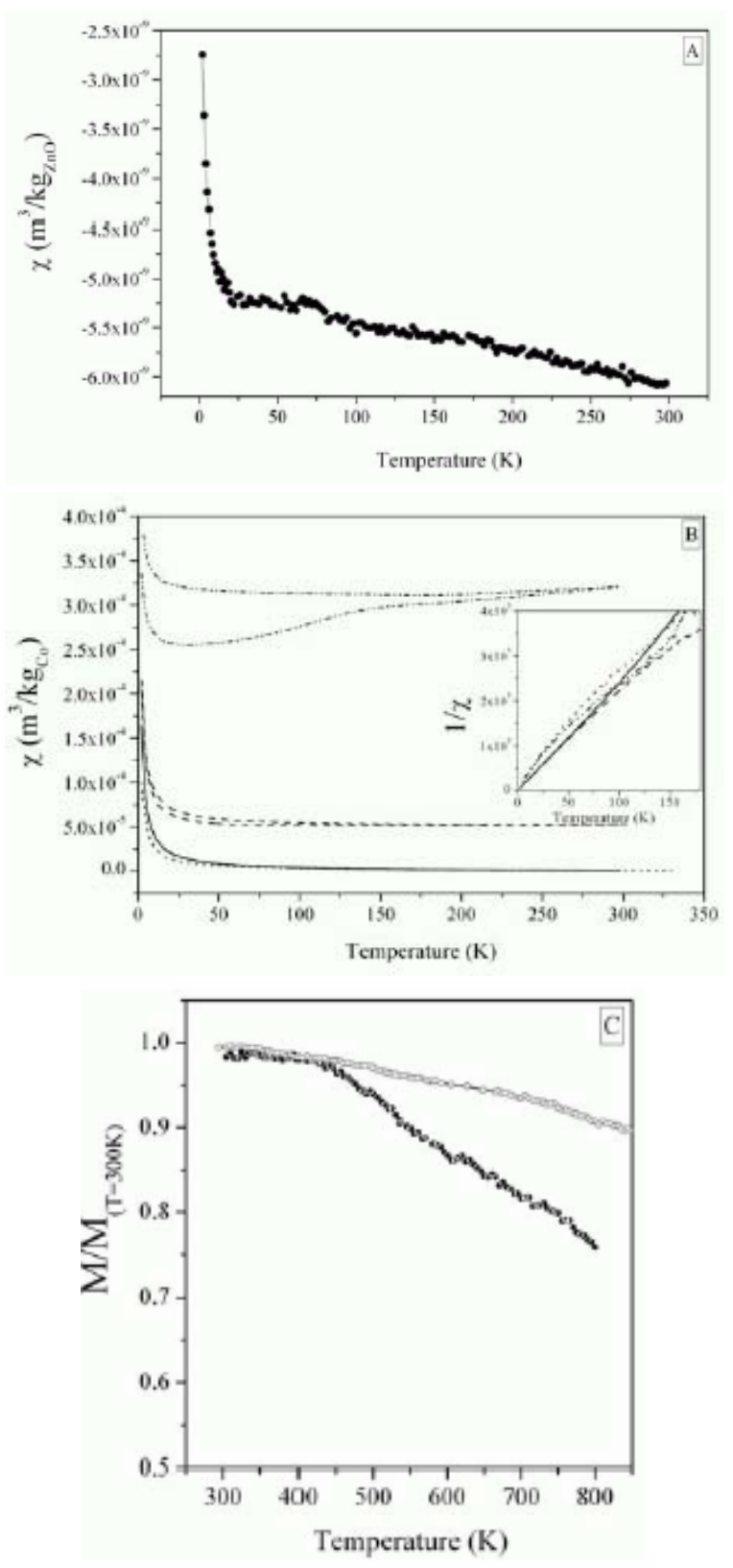

Figure 12: (A) ZFC magnetization curve of pure $\mathrm{ZnO}$ synthesized in benzyl alcohol. (B) ZFC-FC magnetization curves of $0.81 \%$ Co doped $\mathrm{ZnO}$ synthesized in benzyl alcohol/anisole (5/95) (full line), $4.09 \%$ Co doped $\mathrm{ZnO}$ synthesized in benzyl alcohol/anisole (5/95) (dotted line), $0.77 \%$ Co doped $\mathrm{ZnO}$ in pure benzyl alcohol (dashed line), $3.88 \%$ Co doped $\mathrm{ZnO}$ in pure benzyl alcohol (dot-dotdashed line), (inset) the inverse of magnetization for all samples (pure benzyl alcohol sample has been corrected from its ferromagnetic contribution). (C) High temperature magnetization curves of $0.77 \%$ Co doped $\mathrm{ZnO}$ in pure benzyl alcohol (filled round) and $3.88 \%$ Co doped $\mathrm{ZnO}$ in pure benzyl alcohol (unfilled round) (data are normalized to the magnetic moment at $300 \mathrm{~K}$ ).

ascribed to a paramagnetic phase (isolated $\mathrm{Co}^{2+}$ ) and a ferromagnetic phase (coupled $\mathrm{Co}^{2+}$ ) in coexistence. The exchange mechanism remains unclear although the reaction conditions play a key role on the magnetic properties and in particular on the exchange interaction.

High temperature magnetization studies show that the room temperature ferromagnetism is persistent up to
$900 \mathrm{~K}$; the decreasing of the magnetization with temperature is sensitive to the cobalt content (Figure 12C). The behavior of magnetization shows a non-Brilloin type temperature dependence, for various cobalt concentrations which could arise from an intrinsic magnetic effect or from thermal changes in the state of the sample with annealing temperature. It is rather intriguing and promising that the Curie temperature can be so high in an intrinsic DMS system.

For the same cobalt concentration the synthesis in pure benzyl alcohol route leads to a ferromagnetic material unlike the one in benzyl alcohol/anisole (5/95). In the other hand, the paramagnetic contribution for each sample is quantitatively related to the cobalt content and not to the solvent (Figure 12B inset). The nature of the solvent is only relevant to the sign of the exchange interaction between the spins, antiferromagnetic coupling for anisole, ferromagnetic coupling for benzyl alcohol. The same reaction conducted in trioctylamine also leads to a ferromagnetic material for any cobalt concentration [21, 22]. Hence, the solvent plays an important role in the magnetic state and two hypotheses may arise from this statement. (i) The solvent may act as a reducing agent; amines and, to a less extent, alcohols are reducing agents. The cobalt would then be stabilized in two different oxidation states: $\mathrm{Co}^{2+}$ and $\mathrm{Co}^{+}$. $\mathrm{Co}(0)$ is unlikely to be present as already discussed from EPR measurements. Co (I) (valence shell $3 \mathrm{~d}^{7} 4 \mathrm{~s}^{1}$ ) does not present any paramagnetic resonance due to its spin parity. In this case the formation of $\mathrm{Co}^{+}$might mediate the interactions between the $\mathrm{Co}^{2+}$ centers. (ii) On the other hand, benzyl alcohol could also act a strong $\sigma$ - donor ligand on the surface. The carrier concentration would then increase from the particles synthesized in anisole to the ones in pure benzyl alcohol. Some results on nanostructured thin films have shown the effect of varying the carrier concentration by chemisorption of various reducing reagents including amines.[64] The chemical manipulation of magnetic state in $\mathrm{ZnO}$ has been claimed to depend only on the carrier concentration. These results would then be in agreement with the Zener model[2]. Based on the conclusion of studies presented above, we conducted several thermal treatments in presence of the solvents used in the synthesis. The samples synthesized by the benzyl alcohol route were refluxed in anisole for 48 hours in an autoclave. Their magnetic properties at room temperature are displayed in figure 13A. The samples still exhibit a ferromagnetic behavior with no noticeable change. On the other hand, once a sample synthesized following the benzyl alcohol/anisole route has been annealed in benzyl alcohol at $250^{\circ} \mathrm{C}$ for 48 hours; the collected material still displays a paramagnetic behavior as shown on figure 13B. Based on these results, we assume that the magnetic properties observed in our material are not sensitive to the surface state. The observance of ferromagnetism appears to be clearly related to the core properties of cobalt doped $\mathrm{ZnO}$ nanocrystals. 

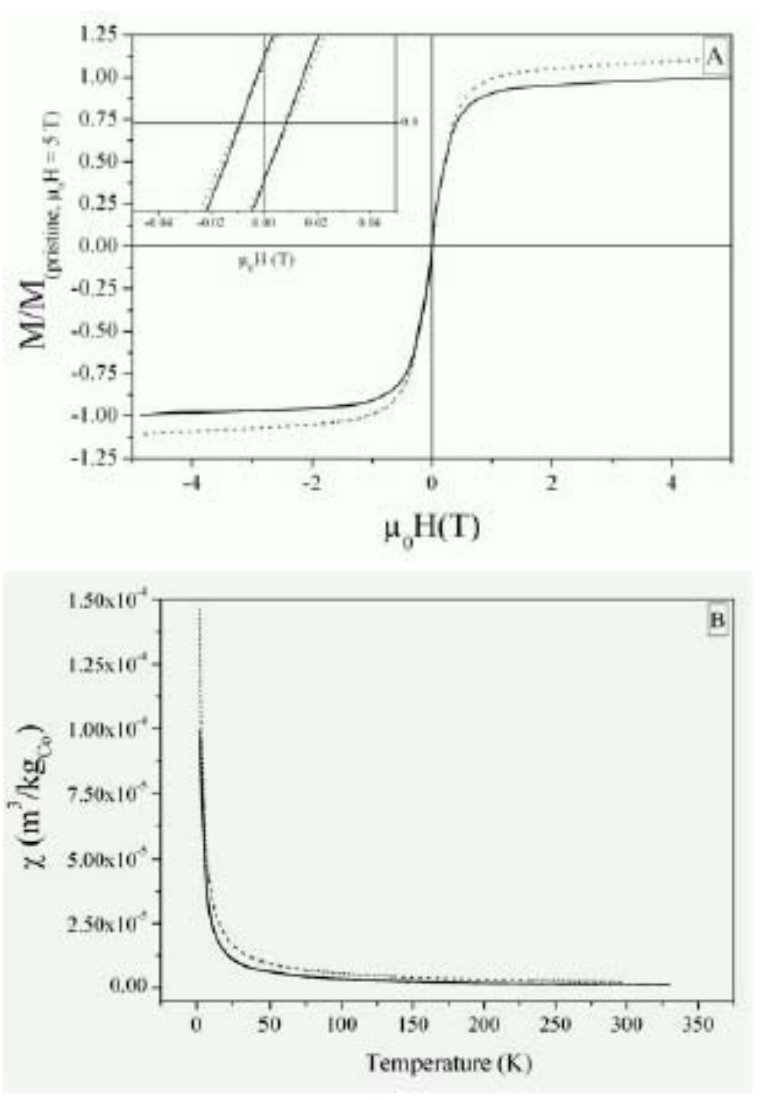

Figure 13: (A) Magnetization versus field of $3.88 \%$ Co doped $\mathrm{ZnO}$ synthesized in pure benzyl alcohol at $300 \mathrm{~K}$ (full line) and after thermal treatment in anisole at $300 \mathrm{~K}$ (dotted line) (data are normalized to the magnetic moment of pristine sample at $\mu_{0} \mathrm{H}=5 \mathrm{~T}$ ). (B) ZFC-FC magnetization curves of $4.09 \%$ Co doped $\mathrm{ZnO}$ synthesized in benzyl alcohol/anisole (5/95) (full line) and after reflux in benzyl alcohol (dotted line).

\section{Conclusion}

In summary, we have synthesized cobalt and manganese doped zinc oxide nanoparticles using a new solvent directed synthesis. The dopant substitutes onto zinc sites in the wurtzite lattice uniformly, with no detectable phase impurities or clustering. Mn-doped nanoparticles display paramagnetism for all temperature range. On the other hand, Co-doped nanoparticles exhibit a dependence of the magnetic behaviour in function of the solvent used. When they are synthesized in pure benzyl alcohol they show a hysteresis effect through a wide temperature range, and display mainly ferromagnetic behavior. The magnetic moment at room temperature reaches the extremely high value of $0.8 \mu_{\mathrm{B}}$ for very low field. The complete EPR and magnetic studies on $\mathrm{Co}$ doped $\mathrm{ZnO}$ allow to ensure that the ferromagnetic behavior is due to $\mathrm{Co}^{2+}$ ions. Finally, the present work brings new insights on the nature of ferromagnetism in Co doped $\mathrm{ZnO}$ along with the ability of elaborating very large scale amount of DMS materials without any inorganic or organic impurity.

\section{Experimental Section}

Zinc(II) acetate $99.99 \%$, Cobalt(II) acetate anhydrous, Anisole 99\% and benzyl alcohol 99\%, were purchased from Aldrich, stored in a dessicator (or a glovebox) and used as received. $\mathrm{Mn}$ (II) oleate was prepared by reacting $\mathrm{Mn}$ (II) chloride and sodium oleate.[65]

In a typical reaction, a Teflon cup of $45 \mathrm{ml}$ inner volume was filled with $2,73 \mathrm{mmol}$ of Zinc(II) acetate, 16 $\mathrm{ml}$ of anisole and $800 \mu \mathrm{l}$ of benzyl alcohol for the "benzyl alcohol/anisole (5/95)" synthesis or with $16 \mathrm{ml}$ of benzyl alcohol for the pure benzyl alcohol route. Then, the cup was slipped into a steel autoclave, sealed and heated at 250 ${ }^{\circ} \mathrm{C}$ for 2 days. The resulting suspensions were centrifuged, and the precipitates were meticulously washed with ethanol and dichloromethane and then dried in air at $80{ }^{\circ} \mathrm{C}$. The quantity of nanocrystals produced was approximately 170 $\mathrm{mg}$ (yield $>70 \%$ ). In the case of the $\mathrm{Co}(\mathrm{II})-$ and $\mathrm{Mn}(\mathrm{II})$ doped $\mathrm{ZnO}$ x-equivalents of transition-metal doping were added to the reaction mixture, in that case, green and yellow powder were obtained respectively. The "anisole with trace of benzyl alcohol" route was carried out in an autoclave previously used with benzyl alcohol only as solvent. In fact, we have quantified by GC/MS that a $45 \mathrm{ml}$ Teflon cup can stock and liberate up to $200 \mu \mathrm{l}$ of solvent inside its walls. As anisole is an inert solvent, the traces of benzyl alcohol allow the reaction. The larger aspect ratio obtained in this case is certainly due to the continuous and slow supply of the reacting solvent. We assume that this method is unconventional and we present here these results only with the purpose to illustrate the decisive role of the solvent and the importance of the kinetic on the growth of $\mathrm{ZnO}$.

The X-ray powder diffraction (XRD) data were collected on an X'Pert MPD Philips diffractometer (CuK $\alpha$ Xradiation at $40 \mathrm{kV}$ and $50 \mathrm{~mA}$ ). Scanning electron microscopy (SEM) images were performed using a FEG-SEM Hitachi S4100 microscope operating at $25 \mathrm{kV}$. The samples were prepared by depositing a drop of a suspension of the particles in ethanol onto a glass piece which was then coated by carbon. Transmission electron microscopy (TEM) was carried out on a Hitachi H-9000 microscope operating at $300 \mathrm{kV}$, high resolution microscopy and EDX measurements were performed on a CM200FEG (Philips) microscope, operated at $200 \mathrm{kV}$, equipped with a field emission gun. Samples were prepared by depositing a drop of a solution of particles in ethanol on a copper grid coated with an amorphous carbon film. Diffuse reflectance UV/Visible was performed on Jasco V-560 UV/Vis spectrophotometer. FTIR spectra were measured on a Matson 7000 FTIR spectrometer from $\mathrm{KBr}$ pellets. Inductively Coupled Plasma-Atomic Emission Spectrometry (ICPAES) was realized in the Analytical Laboratories of University of Aveiro. Nuclear Magnetic Resonance (NMR) was performed with a Brucker instrument at $300 \mathrm{MHz}$ using DMSO-d6 as solvent. ${ }^{1} \mathrm{H}$ NMR spectra of final reaction mixture depict: Benzyl alcohol, $\delta(\mathrm{ppm}): 4,55\left(\mathrm{td}, 2 \mathrm{H}, \mathrm{CH}_{2}\right.$, $\left.{ }^{3} \mathrm{~J}_{\mathrm{H}-\mathrm{H}}=5.4 \mathrm{~Hz}\right), 5.27\left(\mathrm{t}, \mathrm{H}, \mathrm{OH},{ }^{3} \mathrm{~J}_{\mathrm{H}-\mathrm{H}}=5.4 \mathrm{~Hz}\right), 7.34(\mathrm{~m}, 5 \mathrm{H}$, 
$\left.\mathrm{C}_{6} \mathrm{H}_{5}\right)$. Benzyl acetate, $\delta(\mathrm{ppm}): 2.07\left(\mathrm{~s}, 3 \mathrm{H}, \mathrm{CH}_{3}\right), 5.1(\mathrm{~s}$, $\left.2 \mathrm{H}, \mathrm{CH}_{2}\right), 7.26\left(\mathrm{~m}, 5 \mathrm{H}, \mathrm{C}_{6} \mathrm{H}_{5}\right)$. Water, $\delta(\mathrm{ppm}): 3.54(\mathrm{~s}$, $\left.\mathrm{H}_{2} \mathrm{O}\right)$. The EPR experiments were performed at $X$ band $\sim 9.5 \mathrm{GHz}$ on a Brucker ESP300 spectrometer with microwave powers between 0.02 and $200 \mathrm{~mW}$. Temperature studies from 4.2 to $300 \mathrm{~K}$ were carried out using an Oxford gas-flow cryostat. Magnetic properties were measured using a SuperQuantum Interference Design (SQUID) magnetometer MPMS XL7, in the range of temperature 2-350 K and of field 0-5 T. The temperature-dependent susceptibility was measured using DC procedure. The sample was

\section{References}

[1] M. H. Huang, S. Mao, H. Feick, H. Q. Yan, Y. Y. Wu, H. Kind, E. Weber, R. Russo, P. D. Yang, Science 2001, 292, 1897.

[2] T. Dietl, H. Ohno, F. Matsukura, J. Cibert, D. Ferrand, Science 2000, 287, 1019.

[3] Y. Ohno, D. K. Young, B. Beschoten, F. Matsukura, H. Ohno, D. D. Awschalom, Nature 1999, 402, 790.

[4] R. Seshadri, Current Opinion in Solid State and Materials Science 2005, 9, 1.

[5] D. C. Kundaliya, S. B. Ogale, S. E. Lofland, S. Dhar, C. J. Metting, S. R. Shinde, Z. Ma, B. Varughese, K. V. Ramanujachary, L. Salamanca-Riba, T. Venkatesan, Nat. Mater. 2004, 3, 709.

[6] T. Fukumura, Z. W. Jin, A. Ohtomo, H. Koinuma, M. Kawasaki, Appl. Phys. Lett. 1999, 75, 3366.

[7] T. Fukumura, Z. W. Jin, M. Kawasaki, T. Shono, T. Hasegawa, S. Koshihara, H. Koinuma, Appl. Phys. Lett. 2001, 78, 958.

[8] N. S. Norberg, K. R. Kittilstved, J. E. Amonette, R. K. Kukkadapu, D. A. Schwartz, D. R. Gamelin, J. Am. Chem. Soc. 2004, 126, 9387.

[9] J. M. Baik, J. L. Lee, Adv. Mater. 2005, 17, 2745.

[10] Y. Q. Chang, D. B. Wang, X. H. Luo, X. Y. Xu, X. H. Chen, L. Li, C. P. Chen, R. M. Wang, J. Xu, D. P. Yu, Appl. Phys. Lett. 2003, 83, 4020.

[11] J. J. Liu, M. H. Yu, W. L. Zhou, Appl. Phys. Lett. 2005, 87, 172505.

[12] J. J. Liu, M. H. Yu, W. L. Zhou, J. Appl. Phys. 2006, 99, $08 \mathrm{M} 119$.

[13] U. Philipose, S. V. Nair, S. Trudel, C. F. de Souza, S. Aouba, R. H. Hill, H. E. Ruda, Appl. Phys. Lett. 2006, 88, 263101.

[14] P. I. Archer, P. V. Radovanovic, S. M. Heald, D. R. Gamelin, J. Am. Chem. Soc. 2005, 127, 14479.

[15] D. A. Schwartz, N. S. Norberg, Q. P. Nguyen, J. M. Parker, D. R. Gamelin, J. Am. Chem. Soc. 2003, 125, 13205.

[16] K. Ando, H. Saito, Z. W. Jin, T. Fukumura, M. Kawasaki, Y. Matsumoto, H. Koinuma, Appl. Phys. Lett. 2001, 78, 2700.

[17] L. W. Yang, X. L. Wu, T. Qiu, G. G. Siu, P. K. Chu, J. Appl. Phys. 2006, 99, 074303.

[18] J. J. Wu, S. C. Liu, M. H. Yang, Appl. Phys. Lett. 2004, 85, 1027.

[19] J. B. Cui, Q. Zeng, U. J. Gibson, J. Appl. Phys. 2006, 99, $08 \mathrm{M} 113$.

[20] J. B. Cui, U. J. Gibson, Appl. Phys. Lett. 2005, 87, 133108.

[21] B. D. Yuhas, D. O. Zitoun, P. J. Pauzauskie, R. R. He, P. D. Yang, Angew. Chem., Int. Ed. 2006, 45, 420.

[22] G. Clavel, N. Pinna, D. Zitoun, Phys. Status Solidi A 2007, 204, 118. cooled to $1.8 \mathrm{~K}$ under zero magnetic field, low magnetic field $(5-50 \mathrm{mT})$ was applied and data collected from $2 \mathrm{~K}$ to $350 \mathrm{~K}$ (zero-field cooled, ZFC). Field Cooled (FC) measurements were performed from $2 \mathrm{~K}$ to $350 \mathrm{~K}$ with an applied field during the cooling. High temperature magnetic measurements were performed on a Vibrating Sample Magnetometer (VSM) from Maglab Oxford Instrument operating at $\mathrm{T}=300-1000 \mathrm{~K}$ under a field of $\mu_{0} \mathrm{H}=$

[23] M. Niederberger, G. Garnweitner, N. Pinna, G. Neri, Prog. Solid State Chem. 2005, 33, 59.

[24] M. Niederberger, G. Garnweitner, J. Buha, J. Polleux, J. Ba, N. Pinna, J. Sol-Gel Sci. Technol. 2006, 40, 259.

[25] M. Niederberger, G. Garnweitner, Chem.-Eur. J. 2006, 12, 7282.

[26] N. Pinna, G. Neri, M. Antonietti, M. Niederberger, Angew. Chem., Int. Ed. 2004, 43, 4345.

[27] M. Havecker, N. Pinna, K. Weiss, H. Sack-Kongehl, R. E. Jentoft, D. Wang, M. Swoboda, U. Wild, M. Niederberger, J. Urban, D. S. Su, R. Schlogl, J. Catal. 2005, 236, 221.

[28] N. Pinna, S. Grancharov, P. Beato, P. Bonville, M. Antonietti, M. Niederberger, Chem. Mater. 2005, 17, 3044.

[29] M. Niederberger, G. Garnweitner, F. Krumeich, R. Nesper, H. Colfen, M. Antonietti, Chem. Mater. 2004, 16, 1202.

[30] J. Joo, S. G. Kwon, J. H. Yu, T. Hyeon, Adv. Mater. 2005, 17, 1873.

[31] L. Yang, G. Wang, C. Tang, H. Wang, L. Zhang, Chem. Phys. Lett. 2005, 409, 337.

[32] E. A. Meulenkamp, J. Phys. Chem. B 1998, 102, 5566.

[33] C. Pacholski, A. Kornowski, H. Weller, Angew. Chem., Int. Ed. 2002, 41, 1188.

[34] R. D. Yang, S. Tripathy, Y. Li, H.-J. Sue, Chem. Phys. Lett. 2005, 411, 150.

[35] X. F. Wang, J. B. Xu, B. Zhang, H. G. Yu, J. Wang, X. Zhang, J. G. Yu, Q. Li, Adv. Mater. 2006, 18, 2476.

[36] X. F. Wang, J. B. Xu, N. Ke, J. G. Yu, J. Wang, Q. Li, H. C. Ong, R. Zhang, Appl. Phys. Lett. 2006, 88, 223108.

[37] H. Du, F. Yuan, S. Huang, J. Li, Y. Zhuy, Chem. Lett. 2004, 33, 770 .

[38] S. K. N. Ayudhya, P. Tonto, O. Mekasuwandumrong, V. Pavarajarn, P. Praserthdam, Cryst. Growth Des. 2006, 6, 2446.

[39] R. A. Laudise, A. A. Ballman, J. Phys. Chem. 1960, 64, 688.

[40] W. J. Li, E. W. Shi, W. Z. Zhong, Z. W. Yin, J. Cryst. Growth 1999, 203, 186.

[41] M. A. Verges, A. Mifsud, C. J. Serna, J. Chem. Soc., Dalton Trans. 1990, 86, 959.

[42] N. Pinna, G. Garnweitner, P. Beato, M. Niederberger, M. Antonietti, Small 2005, 1, 112.

[43] M. Monge, M. L. Kahn, A. Maisonnat, B. Chaudret, Angew. Chem., Int. Ed. 2003, 42, 5321.

[44] H. A. Weakliem, J. Chem. Phys. 1962, 36, 2117.

[45] P. Koidl, Phys. Rev. B 1977, 15, 2493.

[46] S. Deka, P. A. Joy, Solid State Commun. 2005, 134, 665.

[47] C. B. Fitzgerald, M. Venkatesan, J. G. Lunney, L. S. Dorneles, J. M. D. Coey, Appl. Surf. Sci. 2005, 247, 493.

[48] J. H. Kim, H. Kim, D. Kim, S. G. Yoon, W. K. Choo, Solid State Commun. 2004, 131, 677. 
[49] Z. W. Jin, T. Fukumura, M. Kawasaki, K. Ando, H. Saito, T. Sekiguchi, Y. Z. Yoo, M. Murakami, Y. Matsumoto, T. Hasegawa, H. Koinuma, Appl. Phys. Lett. 2001, 78, 3824.

[50] C. N. R. Rao, F. L. Deepak, J. Mater. Chem. 2005, 15, 573

[51] J. K. Furdyna, J. Appl. Phys. 1988, 64, R29.

[52] N. Feltin, L. Levy, D. Ingert, M. P. Pileni, J. Phys. Chem. B 1999, 103, 4

[53] D. Magana, S. C. Perera, A. G. Harter, N. S. Dalal, G. F. Strouse, J. Am. Chem. Soc. 2006, 128, 2931.

[54] P. A. G. Beermann, B. R. McGarvey, S. Muralidharan, R. C. W. Sung, Chem. Mater. 2004, 16, 915.

[55] S. K. Misra, S. I. Andronenko, K. M. Reddy, J. Hays, A. Punnoose, J. Appl. Phys. 2006, 99, 08M106.

[56] H. Zhou, D. M. Hofmann, A. Hofstaetter, B. K. Meyer, J. App. Phys. 2003, 94, 1965.

[57] A. Bencini, C. A. Ghilardi, A. Orlandini, S. Midollini, C. Zanchini, J. Am. Chem. Soc. 1992, 114, 9898.

[58] R. Della Pergola, A. Fumagalli, F. F. de Biani, L. Garlaschelli, F. Laschi, M. C. Malatesta, M. Manassero, E. Roda, M. Sansoni, P. Zanello, Eur. J. Inorg. Chem. 2004, 3901.

[59] J. Osuna, D. deCaro, C. Amiens, B. Chaudret, E. Snoeck, M. Respaud, J. M. Broto, A. Fert, J. Phys. Chem. 1996, 100, 14571.
[60] M. Respaud, M. Goiran, J. M. Broto, F. H. Yang, T. OuldEly, C. Amiens, B. Chaudret, Phys. Rev. B 1999, 59, R3934.

[61] M. Respaud, J. M. Broto, H. Rakoto, A. R. Fert, L. Thomas, B. Barbara, M. Verelst, E. Snoeck, P. Lecante, A. Mosset, J. Osuna, T. O. Ely, C. Amiens, B. Chaudret, Phys. Rev. B 1998, 57, 2925.

[62] D. Zitoun, M. Respaud, M. C. Fromen, M. J. Casanove, P. Lecante, C. Amiens, B. Chaudret, Phys. Rev. Lett. 2002, 89, 037203.

[63] R. Munoz-Espi, G. Jeschke, I. Lieberwirth, C. M. Gomez, G. Wegner, J. Phys. Chem. B 2007, 111, 697.

[64] K. R. Kittilstved, D. A. Schwartz, A. C. Tuan, S. M. Heald, S. A. Chambers, D. R. Gamelin, Phys. Rev. Lett. 2006, 97, 037203.

[65] J. Park, K. J. An, Y. S. Hwang, J. G. Park, H. J. Noh, J. Y. Kim, J. H. Park, N. M. Hwang, T. Hyeon, Nat. Mater. 2004, 3, 891 .

\section{TOC Entry:}

The solvothermal synthesis involving the reaction of zinc and cobalt acetate or manganese oleate with benzyl alcohol leads to pure inorganic nanoparticles that are diluted magnetic semiconductors. Depending on the synthesis conditions cobalt doped particles are paramagnetic or ferromagnetic at room temperature.

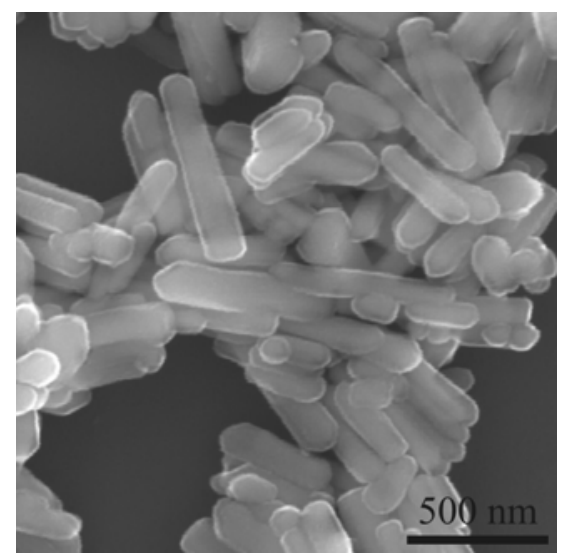

